\title{
Treatment of Halogenated Organic Compounds and Monitoring of Microbial Dynamics in Up-Flow Fixed Bed Reactors Under Sequentially Alternating Pollutant Scenarios
}

\author{
Maria A.E. Emanuelsson, M. Begoña Osuna, Jan Sipma, Paula M.L. Castro \\ Escola Superior de Biotecnologia, Universidade Católica Portuguesa, Rua Dr. António \\ Bernardino de Almeida, 4200-072 Porto, Portugal; telephone: +351-225580059; \\ fax: +351-225090351; e-mail: plcastro@esb.ucp.pt
}

\begin{abstract}
Two up-flow fixed bed reactors (UFBR) were operated for 8 months treating a model synthetic wastewater containing 2-fluorobenzoate (2-FB) and dichloromethane (DCM). The stability of the reactors under dynamic conditions, that is, sequentially alternating pollutants (SAP), shock loads, and starvation periods was assessed. Two support materials were used: expanded clay (EC) that does not adsorb 2-FB or DCM, and granular-activated carbon (GAC) that adsorbs $180 \mathrm{mgg}^{-1}$ of $2-\mathrm{FB}$ and $390 \mathrm{mg} \mathrm{g}^{-1}$ of DCM. The reactors were inoculated with a 2-FB-degrading strain (FB2) and a DCM degrader (TM1). 2-FB was fed at organic loads ranging from 0 to $800 \mathrm{mg} \mathrm{L}^{-1} \mathrm{~d}^{-1}$, while DCM was fed at $0-250 \mathrm{mg} \mathrm{L}^{-1} \mathrm{~d}^{-1}$. 2-FB or DCM were never detected at the outlet of the GAC reactor, while in the EC reactor outlet small amounts were observed. Nevertheless, the highest biological elimination capacity was observed in the EC reactor (over $700 \mathrm{mg} \mathrm{L}^{-1} \mathrm{~d}^{-1}$ of 2-FB). DGGE analysis revealed a fairly stable bacterial community with the largest shifts occurring during starvation periods and changes in feed composition. Several bacterial strains isolated from the reactors showed capacity for 2-FB degradation, while only strain TM1 degraded DCM.

Biotechnol. Bioeng. 2008;99: 800-810.
\end{abstract}

Keywords up-flow fixed bed reactor; 2-fluorobenzoate; dichloromethane; biodegradation sequentially alternating pollutants; microbial dynamics

\section{Introduction}

Halogenated organic compounds are commonly used in the production of various chemicals, pharmaceuticals, herbicides, and pesticides. Due to their chemical stability they tend to accumulate in the environment and may ultimately cause a threat to both the environment and human health. Several studies focused on microbial degradation of both aromatic and aliphatic-chlorinated organic compounds (Hardman, 1991; Janssen et al., 1995; Solyanikova and Golovleva, 2004), but less attention has been given to fluorinated compounds (Key et al., 1997; Vargas et al., 2000; Carvalho et al., 2002).

Another complication of industrial wastewater treatment is the occurrence of wastewaters containing sequentially alternating organic pollutants (SAP), characterized by situations where pollutant composition changes in cycles of weeks or days. Biological treatment of these waste streams can be problematic since changes in substrate load and composition can result in periods of bacterial starvation and washout, thereby decreasing the effectiveness of the treatment unit (Deshusses et al., 1996). Ferreira Jorge and Livingston (2000a) investigated the degradation of monochlorobenzene and dichloroethane fed alternately to a continuous stirred tank bioreactor inoculated with two suspended strains, each degrading one of the compounds. However, continuously feeding low concentrations of both compounds was deemed necessary to prevent serious accumulation of dichloroethane upon resuming its feeding, but the excessive amounts of carbon fed to the system made this strategy unfeasible. In a follow-up study using an extractive membrane reactor both strains remained active in the biofilm, which considerably improved the response time of the system (Ferreira Jorge and Livingston, 2000b). This shows that immobilized cell bioreactors are more promising for treatment of wastewater with fluctuating loads and changes in pollutants as also shown for their capacity to handle starvation periods (Carvalho et al., 2001; 
Nandy and Kaul, 2001). Goodall and Peretti (1998) and Goodall et al. (1998) reported successful biotreatment of a pollutant stream alternating between meta-nitrobenzoate and para-nitrobenzoate using an airlift reactor with biomass immobilized in sodium alginate beads. If both strains were immobilized on the same bead, a shorter response time was obtained when the feeding changed from one compound to the other, which was ascribed to secreted metabolites that both strains could utilize. For the immobilization of biomass, materials such as granular-activated carbon (GAC), clay, plastic, and glass have been successfully used as carrier material in immobilized cell reactors (Moteleb et al., 2002; Tarre et al., 2004; Cai et al., 2006; Calli et al., 2006). GAC is a material highly suitable for bacterial attachment due to its rough surface and porous structure; an additional advantage of its use as biomass support is its generally high adsorption capacity for many xenobiotic organic compounds (Moteleb et al., 2002; Carvalho et al., 2006; Emanuelsson et al., 2006).

In this study, two immobilized biofilm reactors treating halogenated compounds, containing either GAC or expanded clay as growth support were operated under dynamic conditions, including SAP regime, shock loads, and starvation periods. 2-fluorobenzoate (2-FB) and dichloromethane (DCM) were used as model compounds for halogenated organics employed in the chemical and pharmaceutical industry. The choice for these compounds was based on the availability of previously isolated bacteria in the laboratory and the production of distinct biological degradation product, that is, fluoride and chloride. The aim of this study was to investigate the response of bioreactors to an alternating feeding with two selected halogenated organic compounds, simulating an industrial wastewater laden with xenobiotic compounds. The study focused both on the performance of the bioreactors as well as on the dynamics of the microbial community.

\section{Materials and Methods}

Inocula

Two bacterial strains previously isolated in the laboratory were used; strain FB2 was able to degrade 2-FB and strain TM1 was able to degrade DCM (unpublished data). The two strains were grown in sealed flasks containing minimal medium according to Freitas dos Santos and Livingston (1993) supplied with $100 \mathrm{mg} \mathrm{L}^{-1}$ of either 2-FB or DCM.

\section{Reactor Design and Operation}

The two up-flow fixed bed reactors (UFBR) consisted of cylindrical stainless steel columns $(33 \mathrm{~cm}$ height and $3 \mathrm{~cm}$ internal diameter) provided with sampling ports at its entrance, exit, and middle points (Fig. 1). The columns were packed with either 57 g EC particles (Filtralite 2/4, 2$4 \mathrm{~mm}$ Leca Portugal S.A. Avelar, Portugal) or $57 \mathrm{~g}$ GAC

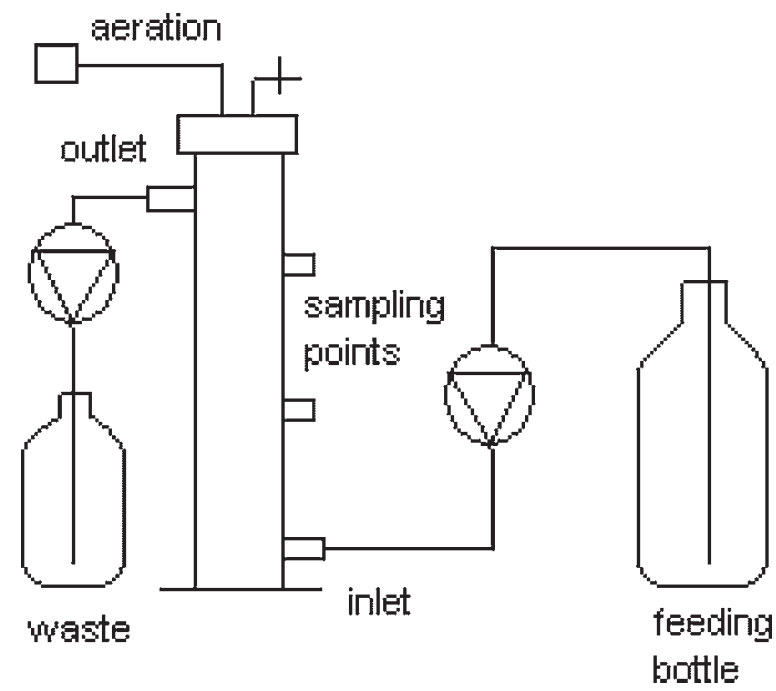

Figure 1. Schematic diagram of the continuous up-flow fixed bed reactor.

(0.85-2.4 mm with a specific surface area of $8 \times 10^{5} \mathrm{~m}^{2} \mathrm{~kg}^{-1}$, Sigma Chemical Co, St Louis, MO), which led to empty bed volumes of $112 \mathrm{~mL}$ and $120 \mathrm{~mL}$, respectively. Prior to its use, the growth support was washed several times with deionized water to remove fine residues, dried in an oven at $105^{\circ} \mathrm{C}$, and autoclaved at $121^{\circ} \mathrm{C}$.

Silicone membranes, permeable to oxygen and pressurized with filtered air, were introduced inside the reactors in order to provide oxygen. The membrane was folded helicoidally around an inert metal support and placed in the center of the reactors. The reactors were operated under non-sterile conditions at ambient temperature $\left(20 \pm 5^{\circ} \mathrm{C}\right)$ and $\mathrm{pH}$ 7. Both reactors were inoculated by recirculating $400 \mathrm{~mL}$ of an inoculum containing both FB2 and TM1, which were separately pre-grown and fed twice with either 2$\mathrm{FB}$ or DCM at $200 \mathrm{mg} \mathrm{L}^{-1}$. Prior to their mixing, the purity of each strain was checked by spreading diluted suspensions onto nutrient broth (NB) agar plates. The mixed inoculum was recirculated through the packed columns for 8 days, at a flow rate of $10 \mathrm{~mL} \mathrm{~h}^{-1}$, to allow colonization of the support materials. The decrease in the optical density $\left(\mathrm{OD}_{600}\right)$ of the recirculating inoculum $(>90 \%)$ was used as an indication of biomass immobilization. The reactors were operated for more than 8 months (Table I) at flow rates between 5 and $8 \mathrm{~mL} \mathrm{~h}^{-1}$, resulting in plugflow conditions in the reactor, and treatment efficiency was monitored by measuring outlet chloride, fluoride, DCM, and 2-FB. The reactors will be referred to as R-EC and R-GAC.

\section{Adsorption Studies of DCM Onto EC and GAC}

To determine the DCM adsorption capacity of the support materials, $0.1 \mathrm{~g}$ of GAC or $5 \mathrm{~g}$ of EC were added to sealed 


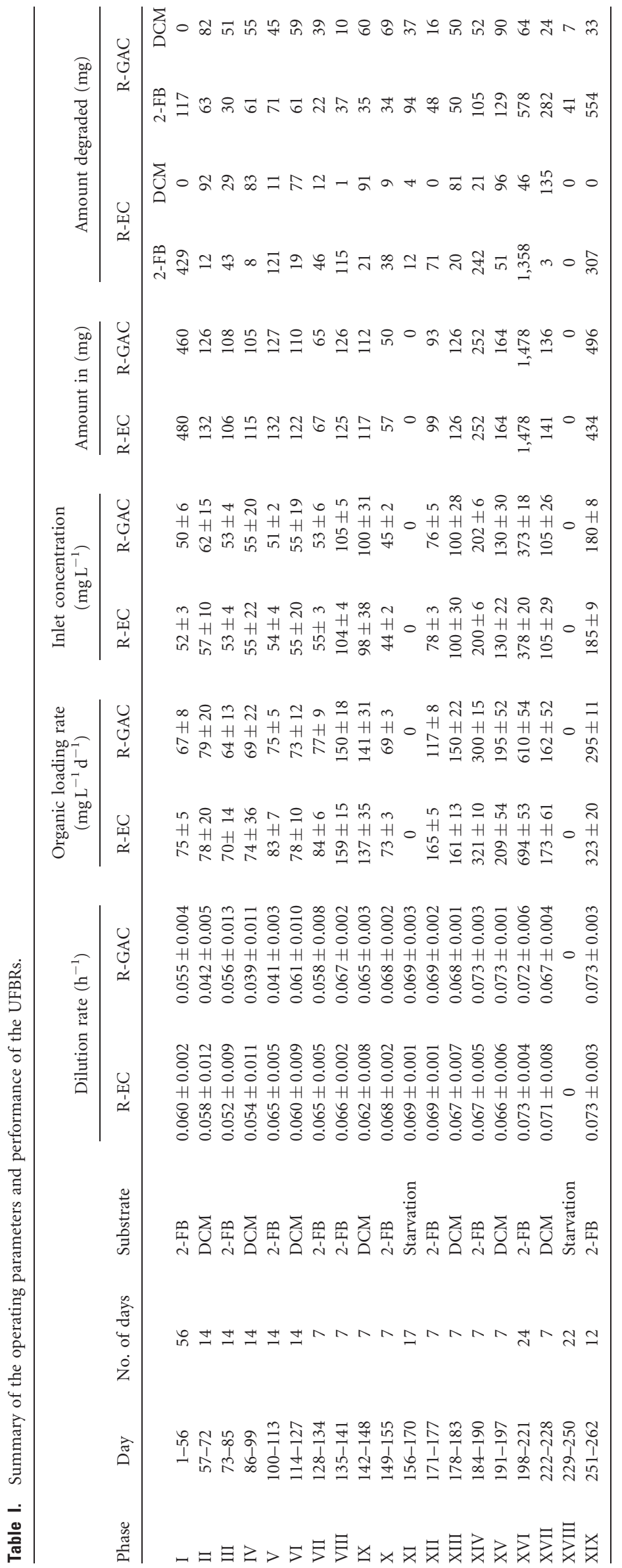


flasks filled with $134 \mathrm{~mL}$ minimal medium and different concentrations of DCM (50-1,500 $\left.\mathrm{mg} \mathrm{L}^{-1}\right)$. The flasks were shaken at $150 \mathrm{rpm}$ at $20^{\circ} \mathrm{C}$ for 1 week. Three replicates were made for each concentration. The same procedure has been described previously for 2-FB (Emanuelsson et al., 2006).

\section{Sampling of Biomass From Support Materials}

EC and GAC samples (1 g wet weight) were collected through two sampling ports of the bioreactors, situated at 11 and $21 \mathrm{~cm}$ from the bottom (Fig. 1). The sample was dispersed in $10 \mathrm{~mL}$ of a $\mathrm{NaCl}$ solution $\left(8.5 \mathrm{~g} \mathrm{~L}^{-1}\right)$, and vortexed for $30 \mathrm{~s}$. The resulting bacterial suspensions were used for plate-counts, bacterial identification, and DNA extraction for DGGE analysis, whereas the support material was returned to the reactor from the top.

\section{Bacterial Counts and Isolation}

Enumeration of bacteria attached to the growth supports was determined by plating serial dilutions of bacterial suspensions in duplicate on NB agar plates. The plates were incubated at $20^{\circ} \mathrm{C}$ for 5 days. At the later stages of bioreactor operation, individual colonies were purified and isolated. These isolates were tested for their capacity to degrade 2-FB and DCM in liquid cultures using shake-flasks containing minimal medium with $50 \mathrm{mg} \mathrm{L}^{-1}$ of either $2-\mathrm{FB}$ or DCM. Strains able to degrade either 2-FB or DCM were kept for further 16S rDNA analysis.

\section{DNA Extraction From Bacterial Suspension and PCR Conditions}

Approximately $8.5 \mathrm{~mL}$ of the bacterial suspensions detached from support materials were centrifuged and washed twice with sterile deionized water. The pellet was kept at $-20^{\circ} \mathrm{C}$ until DNA was extracted. DNA extraction was performed using the UltraClean Microbial Genomic DNA Isolation Kit (Mo Bio, Carlsbad, CA). The extracted DNA was kept at $-20^{\circ} \mathrm{C}$ until its use for DGGE or $16 \mathrm{~S}$ rDNA analysis.

\section{DGGE}

The primers 341F-GC and 518R, specific for conserved bacterial 16S rDNA, were used for amplification of the highly variable V3 region of bacterial $16 \mathrm{~S}$ rDNA corresponding to positions from 341 to 534 of the Escherichia coli numbering (Schäfer and Muyzer, 2001). Primer 341F-GC includes a 39 nucleotide GC rich sequence attached to the $5^{\prime}$ end of the forward primer in order to prevent the complete melting of the PCR products during the subsequent DGGE analysis. PCR conditions have been described before (Emanuelsson et al., 2006).

DGGE analysis was carried out with a DCodeTM Universal Mutation Detection System (Bio-Rad Labora- tories, Hercules, CA). Samples containing approximately equal amounts (ca. $300 \mathrm{ng}$ ) of the PCR products were loaded onto $8 \%$ (wt/vol) polyacrylamide gels (37.5:1, acrylamide: bisacrylamide) in $0.5 \mathrm{X}$ TAE buffer $(20 \mathrm{mM}$ Tris-acetate, $\mathrm{pH}$ 7.4, $10 \mathrm{mM}$ sodium acetate, $0.5 \mathrm{mM} \mathrm{Na} \mathrm{N}_{2}$ EDTA) using a denaturing gradient ranging from $35 \%$ to $60 \%$ (100\% denaturant contains $7 \mathrm{M}$ urea and $40 \%$ formamide). Gel electrophoresis and image capturing was performed as described previously (Emanuelsson et al., 2006). Every gel contained two lanes with a standard of five bands to facilitate the identification of bands occupying the same position in the different lanes of the gels. A binary matrix was constructed taking into account the presence or absence of individual bands in each lane. A similarity matrix was generated using the Bray-Curtis coefficient in the PRIMER v5 software (PRIMER-E Ltd, Plymouth, UK). Dendrograms were generated using the same software with the group average method.

\section{S rDNA Sequencing}

Using the extracted DNA of the isolated strains degrading 2-FB or DCM, the $16 \mathrm{~S}$ rRNA genes were amplified by PCR using the primer set $\mathrm{f} 27$ and r1492 (Lane, 1991) under standard PCR conditions ( 30 cycles of $1 \mathrm{~min}$ at $94^{\circ} \mathrm{C}, 1 \mathrm{~min}$ at $55^{\circ} \mathrm{C}, 1 \mathrm{~min}$ at $72^{\circ} \mathrm{C}$ ) with Taq DNA polymerase (Promega, Madison, WI). The amplified fragments were sequenced by STAB Vida (Oeiras, Portugal).

\section{Analysis}

The fluoride concentration was measured with a fluoride electrode (Carvalho et al., 2002) and the chloride concentration was measured using a colorimetric method (Iwasaky et al., 1956). 2-FB was analyzed by highperformance liquid chromatography (HPLC; Beckman System Gold 126, Fullerton, CA) according to Emanuelsson et al. (2006). DCM was analyzed using gas chromatography, for which $1 \mathrm{~mL}$ of sample was added to a $2 \mathrm{~mL}$ vial containing $0.5 \mathrm{~g}$ of $\mathrm{NaCl}$ and subsequently airtight sealed. The sample was equilibrated for at least $10 \mathrm{~min}$ and the gas phase was injected into a Varian CP 3800 equipped with a Varian capillary column, CP-was $52 \mathrm{CB}, 25 \mathrm{~m}, 0.25 \mathrm{~mm}$, $0.2 \mu \mathrm{m}$ at a constant temperature of $50^{\circ} \mathrm{C}$ for $10 \mathrm{~min}$.

All chemicals used were of analytical grade and were obtained from Sigma-Aldrich Chemie (Steinheim, Germany) or Merck (Darmstadt, Germany).

\section{Results}

Adsorption of the Compounds Onto EC and GAC

EC did not show any capacity to adsorb DCM, while GAC had the capacity to adsorb up to $390 \mathrm{mg} \mathrm{DCM} \mathrm{g}^{-1} \mathrm{GAC}$. The concentrations tested during the experiment were 50, 100, 
170, 400, 700, and $850 \mathrm{mg} \mathrm{L}^{-1}$, which resulted in equilibrium concentrations of $13,48,60,135,181$, and $300 \mathrm{mg} \mathrm{L}^{-1}$, respectively. Previous studies have shown that EC does not adsorb 2-FB while GAC was found to adsorb up

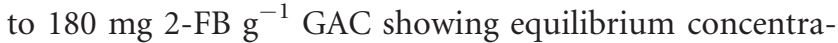
tions of $33,67,213,520$, and $1,315 \mathrm{mgL}^{-1}$ for the concentrations $50,100,250,700$, and $1,500 \mathrm{mg} \mathrm{L}^{-1}$, respectively.

\section{Reactor Performance}

During the first 56 days, the reactors were continuously fed 2 -FB at a constant organic loading rate (OLR) to allow for stable reactor performance and to investigate whether a stable bacterial community would be established (Phase I). From day 56 to day 134, the experiment aimed at investigating the behavior of each reactor in a SAP scenario (Phases II-VII). During these phases 2-FB and DCM were fed alternately with cycles of 2 weeks. The OLR varied between 45 and $83 \mathrm{mg} \mathrm{L}^{-1} \mathrm{~d}^{-1}$ for both compounds. From day 135 onwards (Phases VIII-XIX), the experiment was characterized by shock loads and starvation periods. Details of the feeding parameters are shown in Table I.

\section{Expanded Clay Reactor (R-EC)}

When 2-FB was continuously fed to the reactor at an average OLR of $75 \mathrm{mg} \mathrm{L}^{-1} \mathrm{~d}^{-1}$, no 2-FB was coming out of the reactor. Based on the stoichiometric fluoride release, the 2-FB fed was biologically degraded and a stable degradation of 2-FB was achieved (Fig. 2). DCM was introduced to the reactor on day 57 (Phase II), at $50 \mathrm{mg} \mathrm{L}^{-1}$, and its degradation was detected almost immediately through chloride release at the outlet, although up to $35 \mathrm{mg} \mathrm{L}^{-1}$ DCM was measured at the bioreactor outlet. Four days after its first introduction DCM was no longer detected. During Phases II-VII, the OLR was around $80 \mathrm{mg} \mathrm{L}^{-1} \mathrm{~d}^{-1}$ for both 2-FB and DCM. The reactor responded quickly when the feed was changed from one compound to the other, with negligible or very low concentrations of any compound detected at the outlet, achieving a complete degradation within 1 or 2 days (Fig. 2).

On day 135 the loading of 2-FB was increased to $159 \mathrm{mg} \mathrm{L}^{-1} \mathrm{~d}^{-1}$ (Phase VIII), achieving complete biodegradation rapidly, resulting in an increased biological elimination capacity (BEC) of the reactor. Degradation of DCM also increased when the DCM concentration in the inlet was doubled during Phase IX, reaching a BEC of $150 \mathrm{mg} \mathrm{L}^{-1} \mathrm{~d}^{-1}$. During Phase XI, the reactor was exposed to a starvation period by continuously supplying minimal medium without any substrate to the reactor (Fig. 2). On day 171, when 2-FB feeding was resumed at an OLR of $165 \mathrm{mg} \mathrm{L}^{-1} \mathrm{~d}^{-1}$ (Phase XII), low levels of the compound were detected at the outlet for 3 days only, after which complete degradation was observed. In the following Phase, DCM was re-introduced to the reactor with similar OLR and complete biodegradation of DCM was also observed,

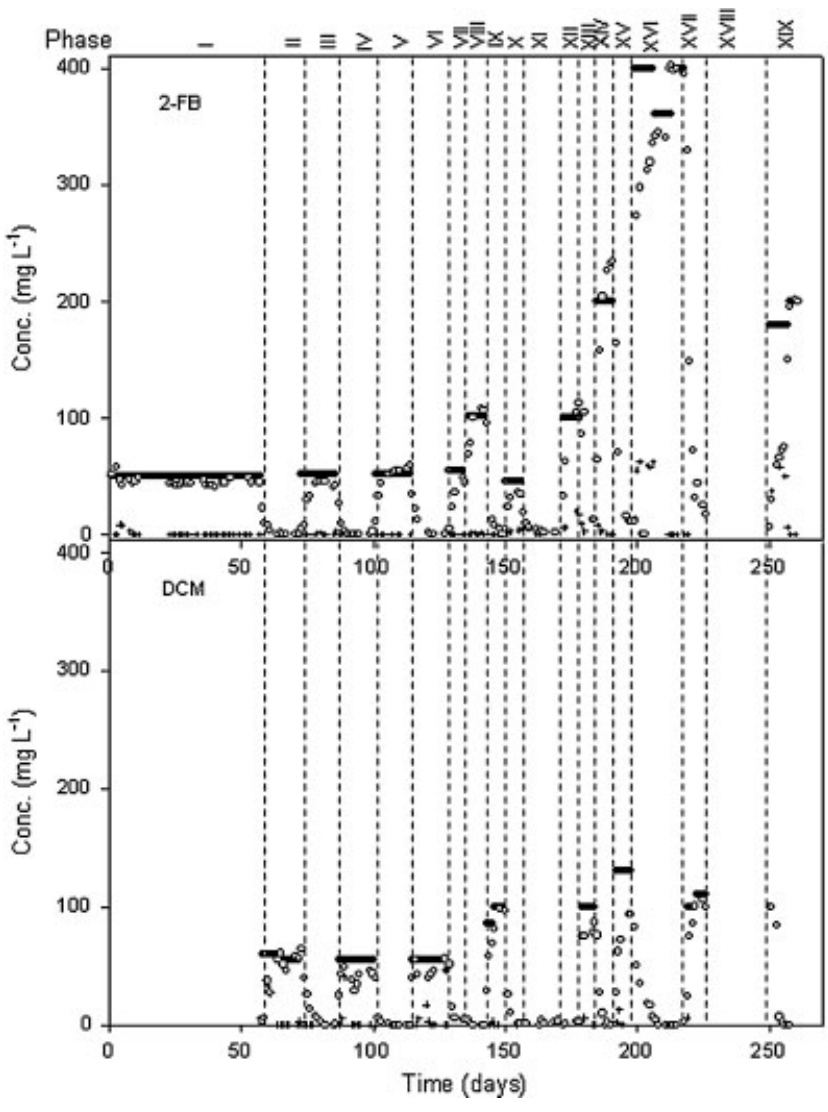

Figure 2. Degradation of 2-FB and DCM in the R-EC operated in continuous mode under a dynamic treatment scenario. Average inlet concentration ( $)$, outlet concentration $(+)$, and degradation based on fluoride or chloride release $(O)$. The different phases of operation are indicated in the figure.

although initially low levels of DCM were detected at the outlet (Fig. 2). In Phase XIV, the bioreactor was able to cope with a further increase in the load of 2-FB to an OLR of 321 $\mathrm{mg} \mathrm{L}^{-1} \mathrm{~d}^{-1}$ (Table I) showing complete biodegradation within a few days. During Phase XV the DCM load doubled to an OLR of $200 \mathrm{mg} \mathrm{L}^{-1} \mathrm{~d}^{-1}$, which led to a higher BEC of $110 \mathrm{mg} \mathrm{L}^{-1} \mathrm{~d}^{-1}$, but coincided with DCM measured at the outlet. An increased OLR of $694 \mathrm{mg} \mathrm{L}^{-1} \mathrm{~d}^{-1}$ of 2-FB was applied to the reactor in Phase XVI, resulting in high concentrations of 2-FB, up to $50 \mathrm{mg} \mathrm{L}^{-1}$, detected at the outlet. Complete biodegradation was not observed until 12 days into that Phase. The highest BEC observed during bioreactor operation of R-EC for 2-FB was over $690 \mathrm{mg} \mathrm{L}^{-1} \mathrm{~d}^{-1}$. When the feed was changed to DCM during Phase XVI, immediate degradation was observed, with the reactor showing a maximum $\mathrm{BEC}$ of $173 \mathrm{mg} \mathrm{L}^{-1} \mathrm{~d}^{-1}$.

The reactor experienced a second starvation period during Phase XVII by disconnecting the inlet to the reactor for 18 days. No 2-FB or DCM was degraded in R-EC during this period. When the feed was reintroduced with an OLR of $300 \mathrm{mg} \mathrm{L}^{-1} \mathrm{~d}^{-1} 2-\mathrm{FB}$, degradation was observed rapidly in the reactor achieving complete biodegradation of all 2-FB fed within 8 days. 
In summary, a total of 3,230 $\mathrm{mg} 2-\mathrm{FB}$, of which 2,916 mg was degraded, and $917 \mathrm{mg}$ DCM, of which $788 \mathrm{mg}$ was degraded, were fed to R-EC (Table I).

\section{Granular-Activated Carbon Reactor (R-GAC)}

No 2-FB or DCM was detected at the outlet of the R-GAC at any time during bioreactor operation due to the adsorption capacity of the support material. Initially, at an OLR of around $70 \mathrm{mg} \mathrm{L}^{-1} \mathrm{~d}^{-1}$, degradation of 2-FB was very low, but slowly increased up to a maximum BEC of $40 \mathrm{mg} \mathrm{L}^{-1} \mathrm{~d}^{-1}$ (Fig. 3). Between day 56 and 134, 2-FB and DCM were alternately fed to the reactor at OLRs of $75 \mathrm{mg} \mathrm{L}^{-1} \mathrm{~d}^{-1}$. When DCM was introduced for the first time (Phase II), degradation was immediately detected and a BEC of $65 \mathrm{mg} \mathrm{L}^{-1} \mathrm{~d}^{-1}$ was reached after 7 days (Fig. 3). 2-FB was continuously degraded in R-GAC between day 56 and 134, even when the compound was not being fed. The same happened for DCM after it was fed for the first time. From day 135 until the end of the experiment (Phases VIII-XIX) shock loads and starvation periods were imposed upon R-GAC. During Phase VIII the 2-FB concentration fed to the reactor was increased to $100 \mathrm{mg} \mathrm{L}^{-1}$. As the OLR increased to $150 \mathrm{mg} \mathrm{L}^{-1} \mathrm{~d}^{-1}$, its degradation also increased reaching a BEC of $72 \mathrm{mg} \mathrm{L}^{-1} \mathrm{~d}^{-1}$. When the DCM inlet load was increased during Phase IX to an average OLR of $138 \mathrm{mg} \mathrm{L}^{-1} \mathrm{~d}^{-1}$, it reached a maximum BEC of $150 \mathrm{mg} \mathrm{L}^{-1} \mathrm{~d}^{-1}$, which indicates that DCM adsorbed to the GAC was also degraded.

During the first starvation period (Phase XI), both 2-FB and DCM were degraded in the reactor (Fig. 3). At day 171, 2-FB was re-introduced at an OLR of $127 \mathrm{mg} \mathrm{L}^{-1} \mathrm{~d}^{-1}$ (Phase XII), and degradation of 2-FB increased (Fig. 3), reaching a maximum BEC of $87 \mathrm{mg} \mathrm{L}^{-1} \mathrm{~d}^{-1}$. In the following Phase, DCM was fed at an average OLR of $150 \mathrm{mg} \mathrm{L}^{-1} \mathrm{~d}^{-1}$, its degradation continued (Fig. 3) and by the end of this Phase the BEC equaled the OLR. In Phase XIV, a further increase in 2-FB loading, up to an OLR of $320 \mathrm{mg} \mathrm{L}^{-1} \mathrm{~d}^{-1}$, led to an increase in its degradation with a maximum BEC of $134 \mathrm{mg} \mathrm{L}^{-1} \mathrm{~d}^{-1}$. During Phase XV the DCM load doubled to an OLR of around $200 \mathrm{mgL}^{-1} \mathrm{~d}^{-1}$, and this increased pollutant concentration increased the BEC to $150 \mathrm{mg} \mathrm{L}^{-1} \mathrm{~d}^{-1}$. An OLR of $610 \mathrm{mg} \mathrm{L}^{-1} \mathrm{~d}^{-1}$ of 2-FB was applied to R-GAC in Phase XVI, leading to a BEC of $450 \mathrm{mg} \mathrm{L}^{-1} \mathrm{~d}^{-1}$, the highest observed for the R-GAC. When the feed was changed to DCM during Phase $\mathrm{XVI}$, immediate degradation of the compound was observed with a BEC of $162 \mathrm{mg} \mathrm{L}^{-1} \mathrm{~d}^{-1}$.

At day 229 a second starvation period (Phase XVII) was imposed upon R-GAC by disconnecting the inlet to the reactor for 18 days. At the end of this Phase high concentrations of chloride and fluoride were measured inside R-GAC, indicating degradation of 2-FB and DCM adsorbed to the carbon. When the feed was reintroduced at an OLR of around $300 \mathrm{mg} \mathrm{L}^{-1} \mathrm{~d}^{-1}$ 2-FB, degradation was observed rapidly and reached a BEC of $250 \mathrm{mg} \mathrm{L}^{-1} \mathrm{~d}^{-1}$ within 5 days.

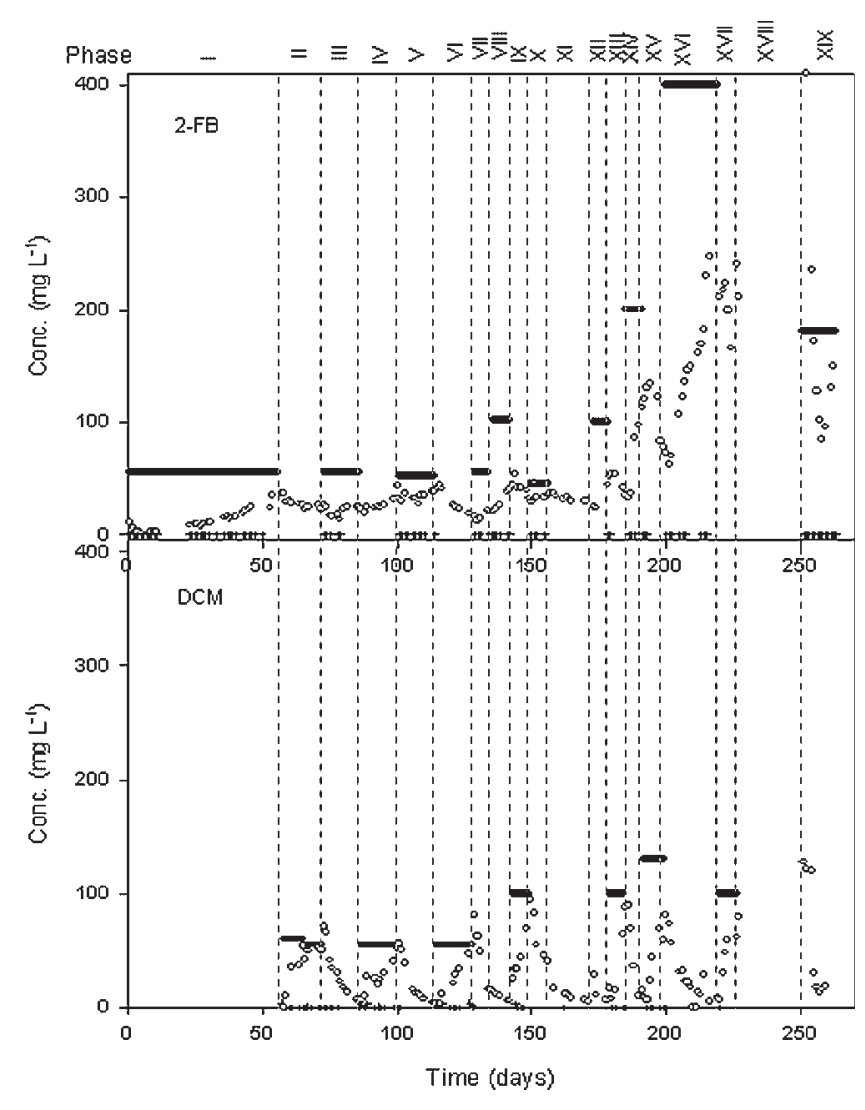

Figure 3. Degradation of 2-FB and DCM in the R-GAC operated in continuous mode under a dynamic treatment scenario. Average inlet concentration ( $)$, outlet concentration $(+)$, and degradation based on fluoride or chloride release $(\bigcirc)$. The different phases of operation are indicated in the figure.

In summary, a total of 3,240 $\mathrm{mg} 2-\mathrm{FB}$, of which $953 \mathrm{mg}$ was degraded, and $925 \mathrm{mg}$ DCM of which $884 \mathrm{mg}$ was degraded, were fed to R-GAC (Table I). This indicates that a large part of the 2-FB fed to this reactor was removed via adsorption to the GAC, whereas DCM was predominantly biodegraded, despite the apparent larger adsorption capacity for DCM. Perhaps the adsorbed DCM was more easily bioavailable than 2-FB.

\section{Microbial Community in the BioPlm Reactors}

The microbial community analyzed during the UFBR operation did not show large variations in terms of bacterial counts with CFU/g support material varying from $5 \times 10^{6}$ to $8 \times 10^{7}$ for the R-EC and from $2 \times 10^{6}$ to $2 \times 10^{7}$ for the R-GAC for samples collected from sampling point P2, situated at the upper part of the reactors. The counts from sampling points $\mathrm{P} 1$, situated on the lower part of the reactor and therefore closer to the inlet, were generally slightly higher: from $8 \times 10^{6}$ to $8 \times 10^{8}$ for the R-EC and from $6 \times 10^{6}$ to $9 \times 10^{7}$ for the R-GAC. The number of viable cells 

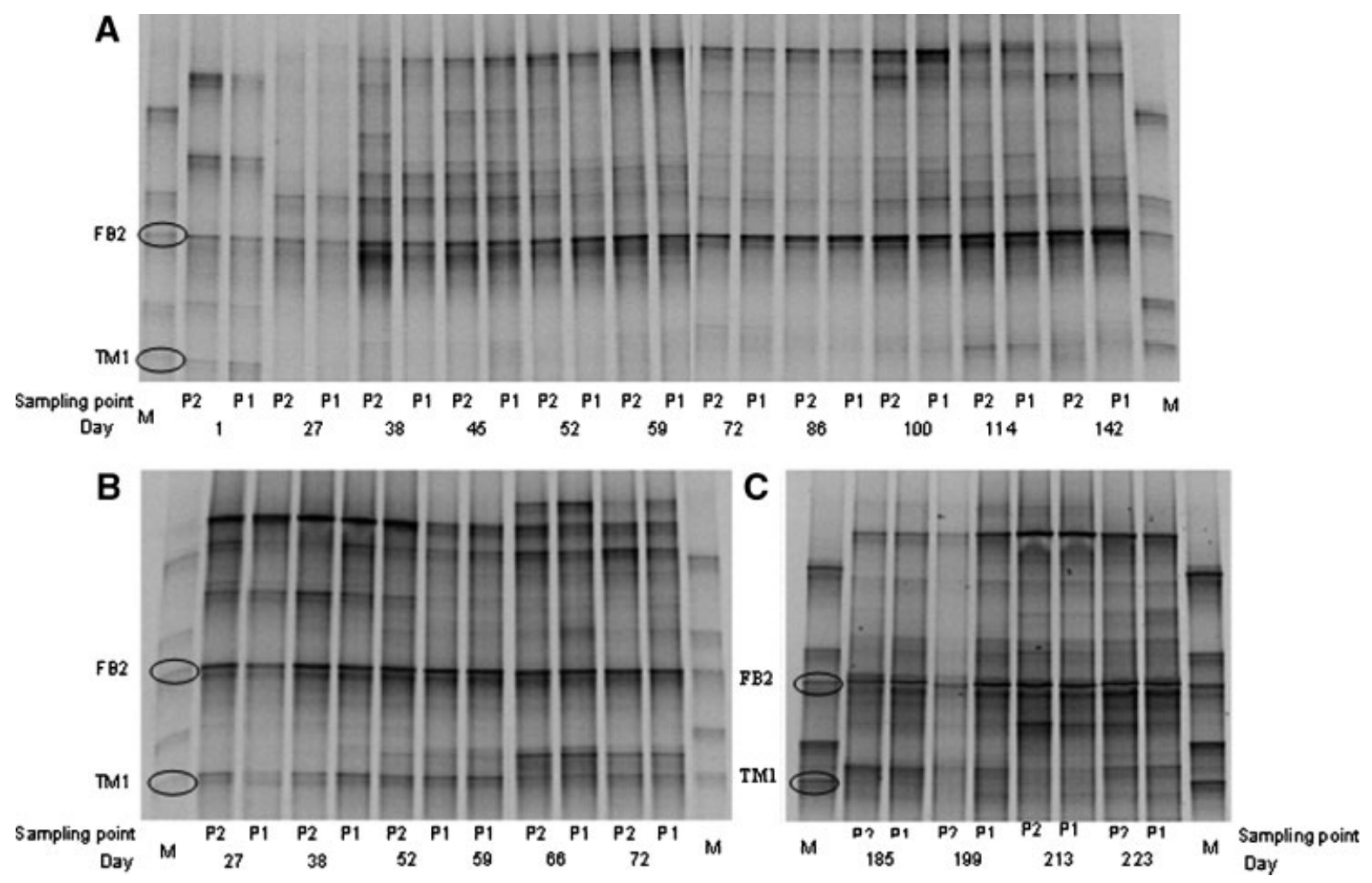

Figure 4. DGGE community fingerprints of the UFBR population. Gel lanes contain PCR-amplified bacterial 16S rRNA gene fragments. Samples collected during continuous feeding of 2-FB and SAP with 2-FB and DCM, (A) from R-EC, (B) from R-GAC, (C) changes occurring in R-EC during shock load and starvation periods. P1: lower sampling point; P2: higher sampling point.

was stable even through the starvation periods, when only small decreases in bacterial counts were observed.

Bacterial community analysis by DGGE showed that strain FB2 was detected in the reactors throughout their operation. In R-EC, strain TM1 was detected at the first sampling stages, on day 1 and 27, but was not detected again until day 72, being observed thereafter (Fig. 4A). In R-GAC, strain TM1 was detected throughout its operation (Fig. 4B). The largest microbial shifts for both reactors were observed between the time of inoculation and starting of the continuous feeding, when both growth supports were quickly colonized not only by the inoculated strains but also by various other bacteria (Fig. 4A,B). By the end of Phase I, the microbial community was fairly stable in both reactors and no big shifts were observed when the feeding was changed to DCM at Phase II; however, during SAP feeding the microbial community seemed to change slightly (Fig. 4A,B). Figure 4C shows DGGE profiles for the R-EC during shock loads and starvation periods.

The dendograms presented in Figure 5A and $\mathrm{B}$ show the overall shifts in the bioreactor microbial communities, which were fairly stable. The shifts were more pronounced in the R-EC. A large shift occurred when SAP feeding started and a second large shift was observed after the first starvation period; three distinct clusters can be seen in the dendogram for the R-GAC microbial community, each representing one of the periods of the feeding strategy (Fig. 5B). For R-EC the largest community shift was observed during starvation periods, although small changes were observed during Phases VIII-XIX, mainly characterized by shock loads and SAP (Figs. 4C and 5A).

\section{Capacity of Bacterial Isolates Recovered From R-EC} and R-GAC to Degrade DCM and 2-FB

None of the bacterial isolates extracted from the reactors, apart from strain TM1, showed degradation activity for DCM while six strains were able to degrade 2-FB. The $16 \mathrm{~S}$ rRNA genes were sequenced and the resulting sequences were submitted to the NCBI database (Table II). DGGE analysis were done for the strains and compared with the DGGE profiles obtained from the reactors. Several of the bands representing these strains corresponded to bands that were often strong and persistent in the DGGE gels done with reactor samples (data not shown).

\section{Discussion}

Two UFBRs were operated for 260 days under various feeding modes showing stable performance during SAP 


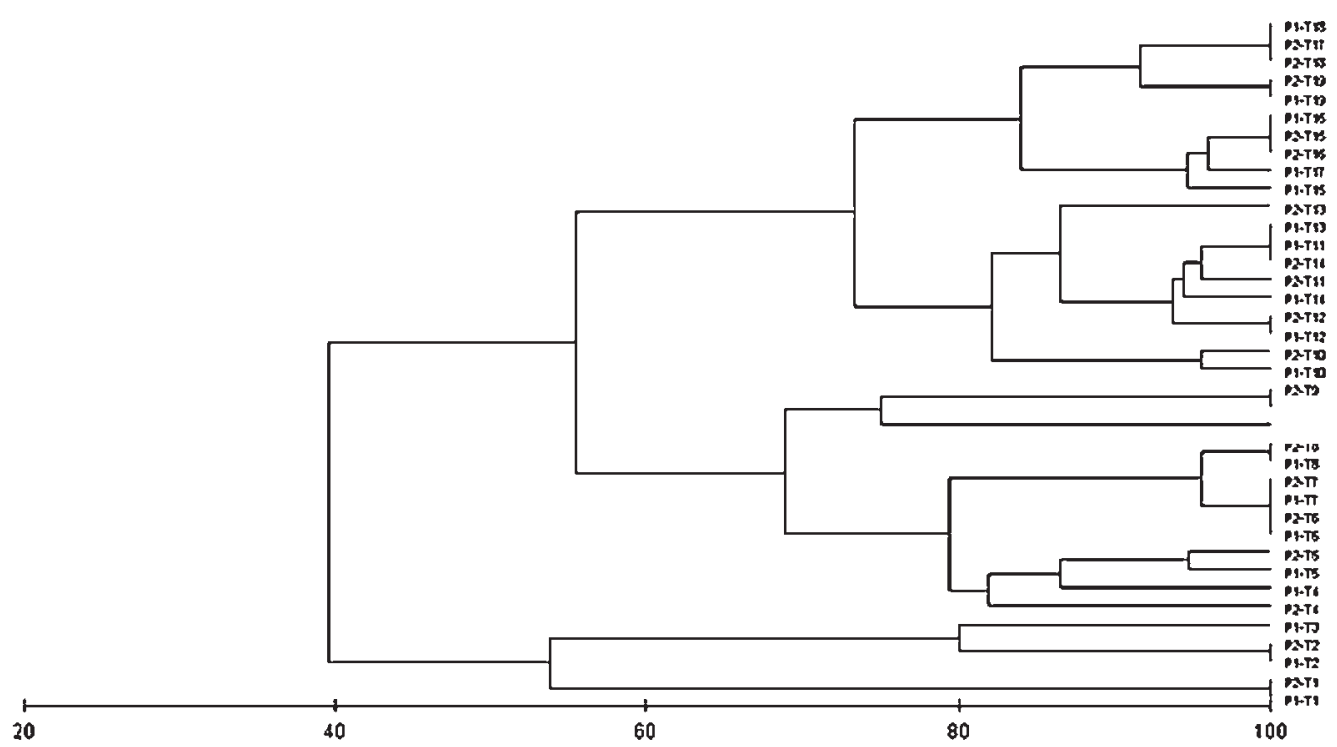

B

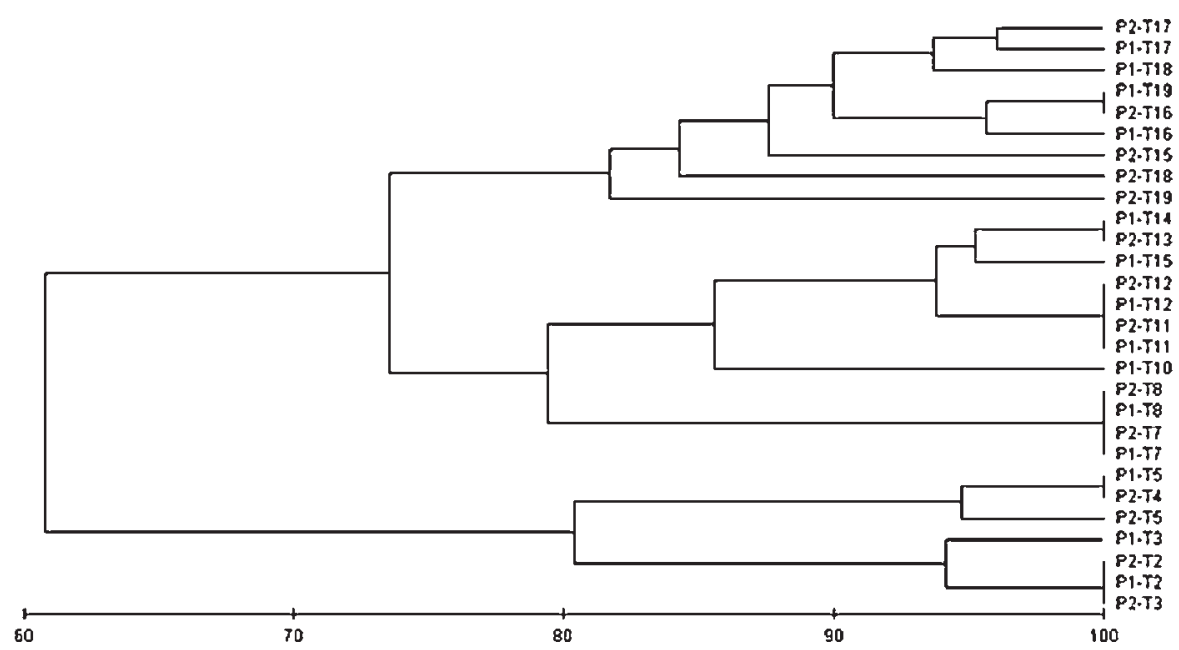

Figure 5. Cluster analysis of the UFBRs bacterial communities based upon DGGE profiles; A: R-EC; B: R-GAC. Similarities were calculated using the Bray-Curtis measure. The dendograms presents the similarity, in percentage, between the DGGE samples. The similarity between specific samples is represented by the node connecting them.

Table II. List of $16 \mathrm{~S}$ rRNA gene analysis of strains enriched from the UFBRs.

\begin{tabular}{lclcl}
\hline Isolate & Accession no. & \multicolumn{1}{c}{ Closest relative } & Homology (\%) & Origin \\
\hline M3 & EF455585 & Acinetobacter calcoaceticul (AY800383.1) & 99 & Isolated from soil \\
M4 & EF455586 & Gordonia sp. D-1 (DQ301916.1) & 99 & DEHP degrader \\
M5 & EF455587 & Uncultured bacteria 26ds5 (AY212720.1) & 99 & Environmental sample \\
& & Pseudomonas sp. M1 (DQ453810.1) & 98 & Isolated from soil \\
M6 & EF455588 & Pimelobacter simplex S151 (AY509240.1) & 98 & Isolated from soil \\
M8 & EF455589 & Methylobacterium sp. 73NP4 (AB242717.1) & Tomato leaf \\
M11 & EF455590 & Uncultured bacterial clone MBR114-46 (AY913834.1) & 99 & Fixed film bioreactor \\
& & Acinetobacter sp. DSM590 (AS16SRRNB) & Not known \\
\hline
\end{tabular}



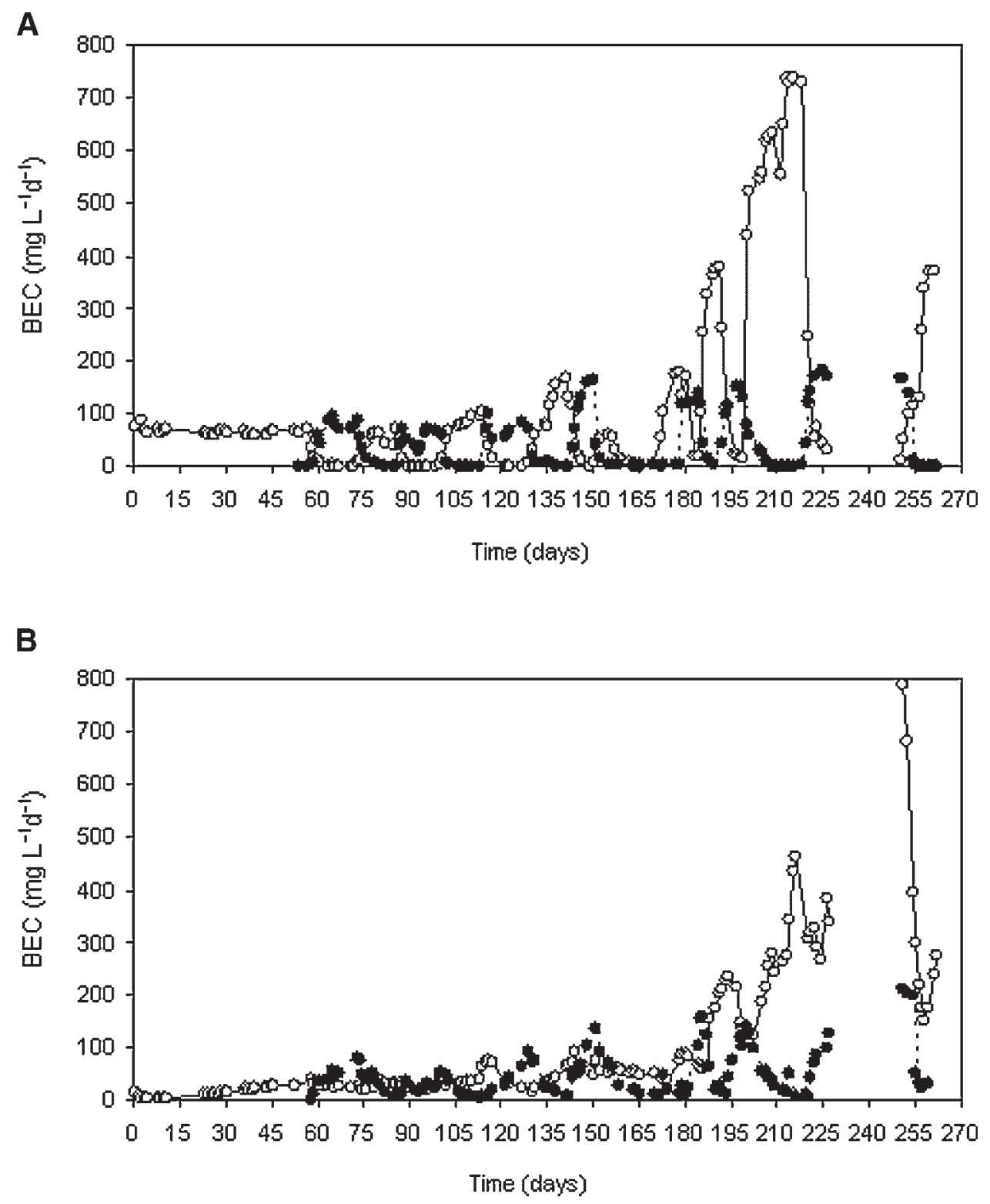

Figure 6. Biological elimination capacity; A: R-EC, B: R-GAC. 2-FB (O), DCM

feeding. At very high OLRs the compounds were initially detected at the outlet of the R-EC, indicating that the system could not immediately handle those shock loads, however, the reactor always recovered within days. The total removal capacity was higher in the R-GAC, but the BEC was in general higher for R-EC, in particular for 2-FB (Fig. 6). Furthermore, when the feed was alternated between compounds a faster response in term of degradation was observed for R-EC than for R-GAC (Fig. 6). As GAC has the capacity to adsorb both compounds it decreases the amount of bioavailable substrate inside the reactor, thus decreasing the BEC. GAC also functions as a buffer and high concentrations or intermittent supply of a compound may not affect the microbial community in such a severe way as in a system without adsorption (Abu-Salah et al., 1996). This is a valuable characteristic when large variations in the OLR occur (Moteleb et al., 2002; Carvalho et al., 2006). For situations where high OLR are applied (700 $\mathrm{mg} \mathrm{d}^{-1} \mathrm{~L}^{-1}$ in this study) the use of GAC as a growth support is a more appropriate strategy, but at lower OLR (ca 70-200 $\mathrm{mg} \mathrm{L}^{-1} \mathrm{~d}^{-1}$ in this study) degradation rates were considerably higher in the EC reactor without leading to high outlet concentrations (Fig. 2). Since EC is considerably cheaper than GAC its use may represent an interesting option under certain conditions of especially low pollutant loads. However, in the case of constant changes in pollutant concentration and composition it is safer and more convenient to use GAC as support material, since it leads 
to constant low concentrations of pollutants in the effluent, which is illustrated in this study by the global superior performance of the GAC reactor, represented by lower amounts of the compound appearing at the outlet of the bioreactors (Fig. 3).

In the present study, during SAP feeding, it is interesting to note that as the feed changed from DCM to 2-FB, an increase in the DCM degradation was immediately observed in R-GAC, which was most likely due to the fact that as 2-FB entered the reactor and adsorbed to the GAC it competed with the DCM already adsorbed resulting in an enhanced bioavailability of DCM. The same effect, although less pronounced, was noted for 2-FB when DCM was introduced. Both reactors were able to deal with shifts in substrate composition, except for periods with very high OLR. In the R-EC there was no adsorption of compounds, implying that constant substrate changes impose greater stress on the microbial community. Despite that, the activity was kept very high in R-EC throughout SAP feeding. DCM, although known to a more toxic compound, did not seem to have a negative effect on the performance of the reactors, not even when they were exposed to high OLR.

The dynamics of the microbial community showed that several bacterial strains colonized the growth support material during inoculation, when the mixed culture of the two strains was recirculated under non-sterile conditions. The microbial communities were fairly stable during reactor operation, changing gradually throughout the experiment, mainly when the feeding strategy changed. When 2-FB was continuously being fed, the bacterial community was stable (Fig. 4A). Stable communities have been reported in previous experiments with similar reactor set-up (Carvalho et al., 2006; Emanuelsson et al., 2006). A large shift was observed in R-GAC when DCM was introduced for the first time (Fig. 5B), while the community in R-EC did not show any significant change at that point (Fig. 5A). A study performed with a trickle-bed air biofilter treating several volatile organic compounds in an alternating mode has shown that there were significant changes in the community after each interchange of volatile organic compound (Cai et al., 2006). Large shifts in microbial communities have been reported both in studies when only one compound was fed continuously (Schlötelburg et al., 2002) and when several substrates were fed (LaPara et al., 2002). In this work, larger shifts were observed for the R-EC than for the R-GAC, which could be due to the fact that both $2-\mathrm{FB}$ and DCM were always present in the R-GAC reactor, and the microbial community did not experience starvation to the same extent as in R-EC.

The stability of the microbial community is most likely due the xenobiotic nature of the substrate fed, limiting the number of microorganisms capable of their degradation. Therefore, it was expected that the inoculated strains play a key role in the community preventing them from being out competed by other strains. Stable microbial communities have been observed previously for degradation of xenobiotic compounds. Emanuelsson et al. (2005) and Baptista et al.
(2006) found very stable microbial communities during continuous feeding of 1,2-dichloroethane in continuous stirred tank bioreactors inoculated with a dichloroethanedegrading strain GJ10, in which strain GJ10 was dominant. However, when glucose was introduced to the system as a second substrate, large shifts in the microbial community were observed and strain GJ10 was no longer the dominant strain. Fairly stable communities during degradation of aromatic compounds such as styrene, benzene, toluene, and fluorobenzene have been reported (Tresse et al., 2002; Smith et al., 2003; Carvalho et al., 2006). In contrast, easily degradable substrates might yield highly variable microbial communities (Fernandez et al., 1999, 2000). The microbial community in a methanogenic reactor fed with glucose for over 600 days changed constantly, although the overall performance of the reactor was very stable (Fernandez et al., 1999). This indicates that the stable reactor performance does not necessarily imply a stable microbial community and vice versa. Higher species diversity or community stability is not directly related to functional stability under pertubated loading of easily degradable compounds (Fernandez et al., 2000). They showed that the more functional stable reactor showed the largest changes in microbial composition. Nevertheless, in case of biotreatment of refractory organics the retention of the specific degrader is desired, which implies a certain need for community stability.

Bacterial isolation performed during the operation of the reactors revealed the presence of several bacterial species capable of 2-FB degradation, including Acinetobacters sp. Pseudmonas sp., Gordonia sp., and Methylobacterium sp. (Table II). These types of bacteria have previously been shown to degrade other aromatic compounds (Bodour et al., 2003; Basu et al., 2006; Geng et al., 2006; Santos et al., 2006). Although several strains were found to degrade 2-FB, the inoculated strain FB2 was present in the reactors throughout their operation, most likely playing a key role in the 2-FB degradation. Apart from strain TM1, none of the strains isolated from the reactors were able to degrade DCM, at least as the sole source of carbon, suggesting that DCM degradation in the reactors was solely performed by strain TM1.

In conclusion, both reactors were able to cope with the SAP feeding and starvation periods imposed. The R-GAC allows for adsorption of the compounds, thus coping well with starvation periods. The R-EC showed higher biological elimination capacity, but the absence of adsorption of pollutants makes it less suitable for operation under higher organic loading rates. These differences in the adsorption capacity are reflected in larger microbial shifts occurring in R-EC, where more sudden changes are experienced by the microbial biofilm.

This work was supported by the European Community's Human Potential Programme under contract HP-RTH-CT-2002-00213 (BIOSAP). 


\section{References}

Abu-Salah K, Shelef G, Levanon D, Armon R, Dosoretz CG. 1996. Microbial degradation of aromatic and polyaromatic toxic compounds adsorbed on powdered activated carbon. J Biotechnol 51:265-272.

Baptista I, Peeva L, Leek D, Zhou N, Mantalaris A, Livingston AG. 2006. Xanthobacter autotrophicus G J10: Stability and performance during 1,2-dichloroethane biodegradation. Appl Environ Microbiol 72:44114418.

Basu A, Apte SK, Phale PS. 2006. Preferential utilization of aromatic compounds over glucose by Pseudomonas putida C SV86. Appl Environ Microbiol 72(3):2226-2230.

Bodour AA, Wang JM, Brusseau ML, Maier RM. 2003. Temporal change in culturable phenanthrene degrader in response to long-term exposure to phenanthrene in a soil column system. Environ Microbiol 5(10):888895.

Cai Z, Kim D, Sorial GA, Saikaly P, Zein MM, Oerther DB. 2006. Performance and microbial diversity of a trickle-bed air biofilter under interchanging contaminants. Eng Life Sci 6(1):37-42.

Calli B, Mertoglu B, Roest K, Inanc B. 2006. Comparison of long-term performances and final microbial compositions of anaerobic reactors treating landfill leachate. Biores Technol 97:641-647.

Carvalho MF, Alves CC, Ferreira MI, De Marco P, Castro PML. 2002. Isolation and initial characterization of bacterial consortia able to mineralize fluorobenzene. Appl Environ Microbiol 68(1):102-105.

Carvalho MF, Ferreira Jorge R, Pacheco CC, De Marco P, Henriques IS, Correira A, Castro PML. 2006. Long term performance and microbial dynamics of an up-flow fixed bed reactor for the treatment of fluorobenzene. Appl Microbiol Biotechnol 71(4):555-562.

Carvalho MF, Vasconcelos I, Bull AT, Castro PML. 2001. A GAC biofilm reactor for the continuous degradation of 4-chlorophenol: Treatment efficiency and microbial analysis. Appl Microbiol Biotechnol 57:419426.

Deshusses MA, Hamer G, Dunn IJ. 1996. Transient-state behavior of a biofilter removing mixtures of vapors of MEK and MIBK from air. Biotechnol Bioeng 49(5):587-598.

Emanuelsson EAC, Baptista I, Mantalaris A, Livingston AG. 2005. Strain stability in biological system treating recalcitrant organic compounds. Biotechnol Bioeng 92:843-849.

Emanuelsson MAE, Henriques IS, Ferreira Jorge RM, Castro PLM. 2006. Biodegradation of 2-fluorobenzoate in up-flow fixed bed bioreactors operated with different growth support materials. J Chem Technol Biotechnol 81(9):1577-1585.

Fernandez A, Huang SY, Seston S, Xing J, Hickey R, Criddle C, Tiedje J. 1999. How stable is stable? Function versus community composition. Appl Environ Microbiol 65:3697-3704.

Fernandez AS, Hashsham SA, Dollhopf SL, Raskin L, Glagoleva O, Dazzo FB, Hickey RF, Criddle CS, Tiedje JM. 2000. Flexible community structure correlates with stable community function in methanogenic bioreactor communities perturbed by glucose. Appl Environ Microbiol 66(9):4058-4067.

Ferreira Jorge RM, Livingston AG. 2000a. Microbial dynamics in a continuous stirred tank bioreactor exposed to an alternating sequence of organic compounds. Biotechnol Bioeng 69:409-417.

Ferreira Jorge RM, Livingston AG. 2000b. Microbial dynamics in an extractive membrane bioreactor exposed to an alternation sequence of organic compounds. Biotechnol Bioeng 70(3):313-322.

Freitas dos Santos LM, Livingston AG. 1993. A novel bioreactor system for the destruction of volatile organic compounds. Appl Microbiol Biotechnol 40:151-157.
Geng A, Soh AE, Lim CJ, Loke LC. 2006. Isolation and characterization of a phenol-degrading bacterium from an industrial activated sludge. Appl Microbiol Biotechnol 71(5):728-735.

Goodall JL, Peretti SW. 1998. Dynamic modeling of meta- and paranitrobenzoate metabolism by a mixed co-immobilized culture of Comamonas spp. JS46 and JS47. Biotechnol Bioeng 59(4):507-516.

Goodall JL, Thomas SM, Spain JC, Peretti SW. 1998. Operation of mixedculture immobilized cell reactors for the metabolism of meta- and paranitrobenzoate by Comamonas sp. JS46 and Comamonas sp. JS47. Biotechnol Bioeng 59(1):21-27.

Hardman DJ. 1991. Biotransformation of halogenated compounds. Crit Rev Biotechnol 11(1):1-40.

Iwasaky I, Utsumi S, Hagino K, Ozawa T. 1956. A new spectrophotometric method for the determination of small amounts of chloride using the mercury thiocyanate method. J Chem Soc Jap 29:860-864.

Janssen DB, van der Ploeg JR, Pries F. 1995. Genetic adaptation of bacteria to halogenated aliphatic compounds. Environ Health Perspect 103(5):29-32.

Key BD, Howell RD, Criddle CS. 1997. Fluorinated organics in the biosphere. Environ Sci Technol 31:2445-2454.

Lane DJ. 1991. 16S/23S rRNA sequencing. In Nucleic acid techniques in bacterial systematics, In: Stackebrandt E, Goodfellow M, editors. Chichester UK: John Wiley and sons. pp. 115-175.

LaPara TM, Nakatsu CH, Pantea LM, Alleman JE. 2002. Stability of the bacterial communities supported by a seven-stage biological process treating pharmaceutical wastewater as revealed by PCR-DGGE. Water Res 36:638-646.

Moteleb MA, Suidan MT, Kim J, Maloney SW. 2002. Pertubated loading of a formaldehyde waste in an anaerobic granular activated carbon fluidized bed reactor. Water Res 35:3775-3785.

Nandy T, Kaul SN. 2001. Anaerobic pre-treatment of herbal-based pharmaceutical wastewater using fixed-film reactor with recourse to energy recovery. Water Res 35:351-362.

Santos SC, Alviano DS, Alviano CS, Padula M, Leitao AC, Martins OB, Riberio CM, Sassaki MY, Matta CP, Bevilaqua J, Sebastian GV, Seldin L. 2006. Characterization of Gordonia sp. Strain F.S.258 capable of dibenzothio-desulfurization and carbazole utilization. Appl Microbiol Biotechnol 71(3):355-362.

Schlötelburg C, von Wintzingerode C, Hauck R, von Wintzingerode F, Hegeman W, Göbel UB. 2002. Microbial structure of an anaerobic bioreactor population that continuously dechlorinates 1,2-dichloropropane. FEMS Microbiol Ecol 39:229-237.

Schäfer H, Muyzer G. 2001. Denaturing gradient gel electrophoresis in marine microbiology. Meth Microbiol 30:425-468.

Smith NR, Yu Z, Mohn WW. 2003. Stability of the bacterial community in a pulp mill effluent treatment system during normal operation and a system shutdown. Water Res 37:4873-4884.

Solyanikova IP, Golovleva LA. 2004. Bacterial degradation of chlorophenols: Pathways, biochemical and genetic aspects. J Environ Sci Health B 39(3):333-351.

Tarre S, Beliavski M, Denekamp N, Gieseke A, de Beer D, Green M. 2004. High nitrification rate at low $\mathrm{pH}$ in a fluidized bed reactor with chalk as the biofilm carrier. Water Sci Technol 49(11-12):99-105.

Tresse O, Lorrain M-J, Rho D. 2002. Population dynamics of free-floating and attached bacteria in a styrene-degrading biotrickling filter analyzed by denaturing gradient gel electrophoresis. Appl Microbiol Biotechnol 59:585-590.

Vargas C, Song B, Camps M, Häggblom MM. 2000. Anaerobic degradation of fluorinated aromatic compounds. Appl Microbiol Biotechnol 53:342-347. 